\title{
Responsabilidade Socioambiental Corporativa e Indicador de Maturidade Mediando Desempenho Estratégico para as Organizações
}

\author{
Giovanni de Araujo Gomes ${ }^{1}$ \\ Carlos Alberto Gonçalves ${ }^{2}$ \\ Daniel Jardim Pardini ${ }^{3}$ \\ Reynaldo Maia Muniz
}

\section{Resumo}

O ambiente de negócios tem apresentado constantes desafios aos dirigentes de empresas. Nesse contexto, a permanente vigilância, reflexo da competitividade e busca de produtividade, faz com as atenções estejam voltadas aos fatores antecedentes e, consequentemente, para a dimensão Responsabilidade Socioambiental Corporativa (RSAC). O trabalho analisa e estima a intensidade das relações entre os fatores valor da marca, reputação da empresa, satisfação dos interessados (stakeholders) e riscos de externalidades, como satélites explicativos da RSAC. E, além dos testes de aderência no modelo relacional, propõe e testa uma equação para dimensionar o grau de Maturidade em Responsabilidade Socioambiental Corporativa Setorial (RSAC), procurando analisar e identificar, em que estágio a RSAC afeta os construtos finais enquanto retorno estratégico para as organizações. Esta pesquisa foi realizada no setor da construção civil de Minas Gerais, representado por seus gestores, e os dados coletados por meio de um survey usando um questionário com questões estruturadas com variação likert. Os dados foram avaliados mediante análise de equações estruturais usando o LVPLS. Para a mensuração das ações em Responsabilidade Socioambiental, utilizaram-se os modelos conhecidos nas organizações e academia, tais como o Índice de Sustentabilidade Empresarial, os Dow Jones Indexes, o indicador do Instituto Ethos e a representação teórica de Hopkins (1997).

Palavras-chave: Modelo de maturidade. Estratégia socioambiental. Índice de maturidade social ambiental. Responsabilidade socioambiental corporativa. Sustentabilidade empresarial.

\footnotetext{
${ }^{1}$ Mestrado em Administração na Universidade FUMEC. Endereço: Av. Afonso Pena, n 3830, Bairro Cruzeiro, CEP: 30.310-190, $1^{\circ}$ andar, Belo Horizonte-MG - Brasil.E-mail: giovanni.araujo@globo.com.

${ }^{2}$ Doutorado em Administração pela Universidade de São Paulo. Professor Associado da UFMG e FUMEC. Endereço: Av. Afonso Pena, n³.830, Bairro Cruzeiro, CEP: 30.310-190, $1^{\circ}$ andar, Belo Horizonte - MG - Brasil. E-mail: carlos@face.ufmg.br.

${ }^{3}$ Doutorado em Administração pela Universidade Federal de Minas Gerais e The Birmingham University. Coordenador do Programa de Doutorado e Mestrado em Administração da Universidade FUMEC. Endereço: Av. Afonso Pena, n³.830, Bairro Cruzeiro, CEP: 30.310-190, $1^{\circ}$ andar, Belo Horizonte - MG - Brasil.E-mail: pardinidaniel@hotmail.com.

${ }^{4}$ Doutorado em Ciência Política e Administração Pública pela Universidad Complutense de Madrid. Vice-diretor da Faculdade de Ciências Econômicas da Universidade Federal de Minas Gerais. Professor associado II da Universidade Federal de Minas Gerais. Endereço: Avenida Antônio Carlos, n 6.627, Campus Pampulha, FACE/UFMG, CEP: 31.270-901, Belo Horizonte - MG -Brasil.E-mail: munizd.bh@terra.com.br.
} 


\section{Introdução}

As atuações das firmas nos ambientes de negócio no estágio atual das relações comerciais têm apresentado importantes desafios para as organizações. A busca por maiores competitividade e produtividade requer consideração às carências e aspirações dos grupos que interferem em sua sustentabilidade (stakeholders ou partes interessadas) e lhes mostra a necessidade de assumir posição gerencial mais aberta, diferente dos primórdios da administração, quando o processo produtivo, ou a capacidade de produção com menores custos e maior qualidade, era o centro das tomadas de decisão. Hoje, a preocupação crescente com os impactos sociais e ambientais de suas ações se faz presente e a Responsabilidade Socioambiental, antes calcada no altruísmo e na caridade, assumiu uma concepção mais abrangente, estratégica.

Para isso, modelos teóricos e práticos de avaliação de ações Socioambientais corporativas foram analisados no decorrer deste trabalho, entre eles, os Dow Jones Sustainability Indexes, da bolsa de Nova Iorque, o Índice de Sustentabilidade Empresarial (ISE), da Bovespa Holding, os Indicadores Ethos de Responsabilidade Social Empresarial, do Instituto Ethos, e a representação de Hopkins (1997).

A pesquisa se propõe aos seguintes objetivos: (i) apresentar um modelo teórico e mensurar com qual intensidade o Desenvolvimento em Responsabilidade Socioambiental Corporativa - RSAC é explicado por ações nos âmbitos de Responsabilidade Ambiental e Responsabilidade Social; (ii) mensurar com qual intensidade a RSAC explica o desempenho plural formado pelos construtos Agregação de valor à marca, melhoria da Reputação da empresa, aumento da Satisfação dos stakeholders e na minimização dos Riscos de externalidades (negativas); (iii) propor e mensurar uma equação para avaliar o grau de maturidade de RSAC em setores da economia.

Os resultados buscaram identificar a maturidade em RSAC do setor industrial da construção civil de Minas Gerais demonstrando se os investimentos necessários ou voluntários se traduzem em benefícios para a firma ou se, na percepção dos gestores, traduzem apenas de um centro de custos. 


\section{Proposições Teóricas e Práticas Organizacionais}

A Responsabilidade Social Corporativa desenvolveu-se, segundo os autores Bernardo et al. (2005), Xavier e Souza (200?), Ashley (2002) e Ackerman (1985), a partir do início do Século XX, sendo primeiramente abordados temas de cunho social e agregando, posteriormente, o fator meio ambiente. Esse processo ocorreu gradativamente, dadas as pressões advindas de sindicatos, sociedade e governo, que, aos poucos, obrigaram as organizações a se adequarem, para garantirem um mínimo de sustentabilidade empresarial.

O relatório da Comissão das Comunidades Europeias (2001) ressalta que a responsabilidade social das empresas é, essencialmente, um conceito, segundo o qual elas decidem, numa base voluntária, contribuir para uma sociedade mais justa e um ambiente mais limpo. Essa responsabilidade manifesta-se em relação aos trabalhadores e, mais genericamente, em relação a todas as partes interessadas afetadas pela empresa e que, por seu turno, podem influenciar os seus resultados.

Alguns autores, como Ashley (2002) e Carrol (1991), comentam que a filantropia está mais presente, no mundo empresarial, em razão do aumento da conscientização do consumidor. Maia (2005) acredita que a ênfase em responsabilidade social, além de oferecer bons resultados operacionais, traz fôlego financeiro, melhores produtos e serviços, preços competitivos e contribui para a melhoria da qualidade de vida, desta e das próximas gerações. Entretanto, Melo Neto e Froes (2001) e Grajew (2002) alegam que filantropia não é responsabilidade social. Trata-se apenas de uma ação voluntária, puramente assistencialista, de eficácia limitada, que coloca seus beneficiários em posição de meros receptores de recursos e doações. Os autores propõem que sejam realizados projetos de controle, para avaliar os recursos que estão sendo disponibilizados, por quais motivos e os resultados obtidos.

Quanto às ações ambientais, no início do período industrial, a concepção dominante era a de que todos os recursos naturais fossem renováveis e abundantes, os níveis de poluição e seus impactos sobre a qualidade do ar, da água e do solo permaneciam desconhecidos e a única preocupação consistia em maximizar os processos produtivos, base das teorias primárias da administração. Em 1992, Goldenberg relatou que, a partir do final dos anos 40, esses impactos ambientais começam a ser percebidos no meio científico e, no início dos anos 60 , adquirem dimensão social e política. 
Desde então, as organizações passam a sofrer regulamentações e são condicionadas a dar atenção a suas ações e efeitos ambientais. Em 1972, o Clube de Roma publicou o Relatório Meadows, apontando os limites do crescimento econômico, face ao reconhecimento da finitude dos recursos naturais. Nesse mesmo período, a problemática do meio ambiente emergiu como fenômeno politicamente significativo, por meio da Conferência de Estocolmo, que, em 1979, criou o conceito de desenvolvimento sustentável - ou seja, compatibilidade de crescimento econômico com a preservação do meio ambiente, desde então seriamente considerado por agentes de organizações públicas, privadas, ONGs, movimentos afins e meios acadêmicos.

Em meados dos anos 90, postulou-se uma nova fase histórica, com a integração da gestão ambiental em empresas industriais, quando algumas características se destacariam: (a) a introdução progressiva de uma perspectiva de sustentabilidade; (b) a proliferação dos engajamentos coletivos - como os códigos de conduta, os convênios e os acordos voluntários; (c) a maior interação entre as esferas pública e privada - com a participação dessas instituições na formulação de objetivos e na escolha de instrumentos de política ambiental; (d) o maior envolvimento da sociedade civil organizada - como, por exemplo, através das Organizações Não Governamentais (CORAZA, 2003).

Além disso, Porter e Linde (1995b) ressaltam que padrões ambientais adequadamente desenhados podem estimular inovações, que, por sua vez, podem baixar o custo total de um produto ou lhe agregar valor. Tais inovações permitem às companhias fazerem uso mais adequado de seus meios de produção - desde a matéria-prima até a energia, compensando, dessa forma, o custo da melhoria ambiental. No final das contas, essa melhoria no uso dos meios de produção torna a companhia mais competitiva e não menos acabando, assim, com o impasse.

Um dos principais desafios corporativos da atualidade é com relação à gestão sustentável, que envolve aspectos econômicos, sociais e ambientais, ou seja, gerar lucros para proprietários e acionistas, promover a equidade de distribuição de renda e consideração social, e responsabilidade frente às gerações futuras. A combinação dos três elementos, em tese, contribui para a continuidade da empresa ao longo do tempo, ou seja, sustentabilidade (CORAL, 2002). 


\subsection{Indicadores, Normas e Modelos de RSAC}

O crescente envolvimento das organizações nas causas Socioambientais e a consciência da necessidade de regulamentação interna, com relação às ações entre empresa e funcionário, empresa e fornecedor, entre outros, são observados, inclusive, no mercado financeiro, como fatores importantes de sustentabilidade. A partir de 2005, a Bovespa Holding passou a calcular e divulgar o Índice de Sustentabilidade Empresarial (ISE), que se transformou em referencial do comércio brasileiro. Criado em conjunto com outras instituições, esse indicador, segundo a organização paulista, tem como objetivo refletir o retorno de uma carteira composta por ações de companhias com reconhecido comprometimento com a responsabilidade social e a sustentabilidade, além de atuar como promotor das boas práticas no meio empresarial brasileiro.

A bolsa de valores de Nova Iorque criou o referencial Dow Jones Sustainability Indexes (DJSI), com a finalidade de demonstrar a valorização das ações de organizações engajadas com a responsabilidade social corporativa. Lançado em 1999, numa parceria entre a Dow Jones Indexes e a Sustainable Asset Management (SAM), gestora de recursos suíça, especializada em instituições envolvidas com a Responsabilidade Socioambiental, o DJSI acompanha o desempenho financeiro das empresas líderes da bolsa de Nova Iorque que comungam com a filosofia do desenvolvimento sustentável e da responsabilidade social.

Organizados em sete temas - valores, transparência e governança; público interno; consumidores e clientes; comunidade; governo; sociedade e meio ambiente, os Indicadores Ethos de Responsabilidade Social Empresarial (IERSE) visam gerar relatórios de sustentabilidade, ou seja, medir, divulgar e prestar contas aos stakeholders, internos e externos, do desempenho organizacional para o desenvolvimento sustentável (GRI, 2006).

A representação teórica analisada foi desenvolvida por Michael Hopkins, em 1997, em três níveis: (I) Princípios de Responsabilidade Social; (II) Processos de Capacidade de Resposta Social e (III) Resultados/Ações de Responsabilidade Social. Sua premissa básica consiste numa prática usual e diária de ações de Responsabilidade Social no ambiente interno das corporações, conscientes de que o seu papel na sociedade inclui o exercício do envolvimento nas dimensões: econômica, legal, ética, política e filantrópica.

A observação de todos os indicadores avaliados demonstra uma sintonia entre eles quanto a alguns temas comuns, como responsabilidade interna, 
responsabilidade externa e relacionamento com os stakeholders. Dois quadros de Responsabilidade Socioambiental corporativa (Quadros 1 e 2) foram desenvolvidos por este estudo, apresentando, de forma sintetizada, os índices sociais e ambientais (endógenos e exógenos) que integram os modelos utilizados, tendo como referência os Indicadores de Sustentabilidade Empresarial (ISE). Como o objetivo da pesquisa verificou a influência da Responsabilidade Socioambiental sobre o Valor da marca, a Reputação da empresa, a Satisfação dos stakeholders e o Risco de externalidades (negativas), os aspectos econômicos do ISE e do DJSI foram suprimidos, não se constituindo parte integrante do Quadro 1.

\begin{tabular}{|c|c|}
\hline Politico Social & $\begin{array}{l}\text { - Respeito à privacidade, uso da informação e marketing; } \\
\text { - Compromisso com princípios e direitos fundamentais nas relações de } \\
\text { trabalho, incluindo-se trabalho decente e respeito ao indivíduo; } \\
\text { - Práticas anticorrupção e antipropina; e } \\
\text { - Responsabilidade com os stakeholders internos. }\end{array}$ \\
\hline $\begin{array}{l}\text { Desempenho } \\
\text { Social }\end{array}$ & $\begin{array}{l}\text { - Diversidade e equipe; } \\
\text { - Contratação de trabalhadores terceirizados; } \\
\text { - Contribuição para inovações: criação de empregos diretos e indiretos; e } \\
\text { - Atração e retenção de talentos, incluindo o desenvolvimento do capital humano. }\end{array}$ \\
\hline $\begin{array}{l}\text { Diálogo e } \\
\text { Participação }\end{array}$ & $\begin{array}{l}\text { - Gestão participativa; } \\
\text { - Relação com trabalhadores terceirizados; e } \\
\text { - Governança corporativa. }\end{array}$ \\
\hline $\begin{array}{l}\text { Política } \\
\text { Ambiental }\end{array}$ & $\begin{array}{l}\text { - Compromisso, abrangência de divulgação de políticas e critérios ambientais; } \\
\text { - Adoção formal de uma estratégia ambiental; e } \\
\text { - Estabelecimento de metas e auditoria ambiental. }\end{array}$ \\
\hline $\begin{array}{l}\text { Gerenciamento } \\
\text { de Impacto } \\
\text { Ambiental }\end{array}$ & $\begin{array}{l}\text { - Minimização de entrada e saída e materiais; e } \\
\text { - Gerenciamento do impacto no meio ambiente e do ciclo de vida de produtos. }\end{array}$ \\
\hline $\begin{array}{l}\text { Desempenho } \\
\text { Ambiental }\end{array}$ & $\begin{array}{l}\text { - Consumo de recursos ambientais; } \\
\text { - Emissões e resíduos; e } \\
\text { - Seguro ambiental. }\end{array}$ \\
\hline
\end{tabular}

Quadro 1: Fatores Endógenos da Responsabilidade Socioambiental Corporativa Fonte: Adaptado dos Modelos ISE, DJSI, IERSE e de Hopkins (1997) 


\begin{tabular}{|c|c|}
\hline Ação Social & $\begin{array}{l}\text { - Envolvimento com ações sociais; e } \\
\text { - Financiamento de ações sociais. }\end{array}$ \\
\hline Gestão Social & $\begin{array}{l}\text { - Relação com sindicatos; } \\
\text { - Relação com clientes e consumidores; } \\
\text { - Seleção, relação e parceria com os fornecedores, coibindo o trabalho infantil } \\
\text { e o trabalho forçado à cadeia produtiva; e } \\
\text { - Relação com a comunidade por meio do gerenciamento dos impactos na } \\
\text { comunidade do entorno e bom relacionamento com organizações locais. }\end{array}$ \\
\hline $\begin{array}{l}\text { Governo e } \\
\text { Sociedade } \\
\text { (Social) }\end{array}$ & $\begin{array}{l}\text { - Liderança e influência social; } \\
\text { - Participação em projetos sociais governamentais; } \\
\text { - Transparência política; e } \\
\text { - Construção da cidadania pelas empresas. }\end{array}$ \\
\hline $\begin{array}{l}\text { Cumprimento } \\
\text { Legal (Social) }\end{array}$ & $\begin{array}{l}\text { - Dimensão social do consumo: excelência do atendimento, conhecimento e } \\
\text { gerenciamento dos danos potenciais dos produtos e serviços, política de } \\
\text { comunicação comercial; e } \\
\text { - Sanções judiciais ou administrativas. }\end{array}$ \\
\hline Gestão Ambiental & $\begin{array}{l}\text { - Sistema de gestão ambiental certificado; } \\
\text { - Comunicação com partes interessadas; } \\
\text { - Gerenciamento e monitoramento de fornecedores; e } \\
\text { - Apresentação e divulgação de relatórios ambientais. }\end{array}$ \\
\hline $\begin{array}{l}\text { Responsabilidade } \\
\text { Frente às Gerações } \\
\text { Futuras }\end{array}$ & $\begin{array}{l}\text { - Educação e conscientização ambiental; e } \\
\text { - Compromisso com a melhoria na qualidade ambiental. }\end{array}$ \\
\hline $\begin{array}{l}\text { Cumprimento } \\
\text { Legal (Ambiental) }\end{array}$ & $\begin{array}{l}\text { - Controle de passivos ambientais; } \\
\text { - Requisitos e procedimentos administrativos aberto à comunidade, ONG, } \\
\text { governo, etc; e } \\
\text { - Procedimentos judiciais. }\end{array}$ \\
\hline
\end{tabular}

Quadro 2: Fatores Exógenos da Responsabilidade Socioambiental Corporativa Fonte: Adaptado dos Modelos ISE, DJSI, IERSE e de Hopkins (1997)

Expostos os exemplos de responsabilidade social e ambiental adotados globalmente, seguem os demais construtos que compõem o Modelo de Maturidade proposto por este artigo. 


\subsection{Valor da Marca, Reputação, Satisfação dos Stakeholders e Risco de Externalidade}

Segundo Gonçalves Filho (2006), devido ao aumento da competitividade, a importância da marca tem sido cada vez mais comprovada, estabelecendo, assim, a necessidade de as organizações apresentarem diferenciais e agregarem valor aos produtos e serviços. Dessa forma, o valor da marca (brand equity ou equidade da marca) sobrepõe-se como fator de relevância neste estudo, pela possibilidade de verificar, na visão gerencial, se o Desenvolvimento de Responsabilidade Socioambiental Corporativo determina, sobre ela, impacto financeiro ou institucional significativo, acrescentando-lhe valor.

Uma pesquisa realizada pelo Instituto Ethos de Responsabilidade Social, no período de 2002 a 2004, em 11 cidades brasileiras, com uma amostra de mil pessoas, divididas em cotas de classe social, idade, escolaridade e ocupação, identificou que o consumidor valoriza cada vez mais a atuação socialmente responsável das empresas, o que agrega à marca identidade positiva e estimula sua preferência no momento da compra.

Quanto à reputação da empresa, a Corporate Reputation Watch (2006) alega tratar-se de um juízo de valor que se efetua sobre a imagem estabelecida de algo. O mercado compara o quadro de predicados que ele montou sobre o conceito de determinada companhia com o retrato da empresa ideal, ou o que ele julga ser ideal.

Thomaz e Brito (2007) desenvolveram algumas categorias de atributos, para avaliar a credibilidade das organizações: qualidade dos produtos/ serviços; qualidade do gerenciamento; inovação; responsabilidade social/ ambiental; força financeira; qualidade do marketing; liderança de mercado; qualidade da estratégia; valorização do dinheiro pelos produtos e serviços e habilidade para atrair, desenvolver e reter talentos. Para Oliveira (2007), a reputação é a forma consistente de uma imagem e, portanto, pode ser construída e sustentada em longo prazo.

Outro construto final inserido no modelo refere-se à satisfação das partes interessadas no negócio, sobre a qual Mitchell, Agle e Wood (1997) afirmam que os stakeholders são grupos de pessoas representativos de toda a cadeia produtiva, que, de alguma forma, possuem poder, legitimidade ou urgência em relação à empresa. A importância de cada classe para a organização varia conforme a reunião desses atributos, sendo o poder, entretanto, o mais relevante, 
seguido da legitimidade e urgência, respectivamente. Dessa forma, os grupos possuem influências diferenciadas, de acordo com a natureza das corporações.

Segundo Elkington (1998), a sociedade não está cobrando apenas resultados financeiros, que agreguem vantagem econômica às suas atividades. Outros efeitos são esperados, destacando-se o social e o ambiental, que, para o autor, acrescentam ou destroem valores importantes à sustentabilidade organizacional. Machado et al. (2006) afirmam que a questão, para as empresas de todos os portes, consiste em como agir de forma a garantir a sobrevivência, em longo prazo, diante dos desafios definidos, dentre eles, a satisfação de todas as partes interessadas, com a extensa diversidade de demandas.

Por último, o risco de externalidade é intrínseco à epísteme que orienta a conduta das organizações contemporâneas, uma vez que estão voltadas para a construção do futuro, por meio de planejamento, estratégias e ações (PASSUELLO; SOUZA, 2005). Portanto, os empreendedores, cientes das necessidades Socioambientais advindas das partes interessadas, devem inserir esse aspecto no seu planejamento estratégico, minimizando as prováveis eventualidades que possam afetar a sustentabilidade de suas respectivas empresas, conforme demonstrado na Tabela 1.

Tabela 1: Oportunidades e possíveis riscos dos stakehorlders à organização

\begin{tabular}{|c|c|c|c|c|}
\hline $\begin{array}{l}\text { Stakeholders } \\
\text { envolvidos }\end{array}$ & Contribuição & $\begin{array}{l}\text { Demandas } \\
\text { básicas }\end{array}$ & Oportunidades & $\begin{array}{l}\text { Minimização de } \\
\text { riscos }\end{array}$ \\
\hline Comunidades & Infraestrutura & $\begin{array}{l}\text { Respeito ao } \\
\text { interesse } \\
\text { comunitário. } \\
\text { Contribuição à } \\
\text { melhoria da } \\
\text { qualidade de vida } \\
\text { na comunidade. } \\
\text { Conservação } \\
\text { dos recursos } \\
\text { naturais, etc. }\end{array}$ & $\begin{array}{l}\text { Criação de } \\
\text { legitimidade }\end{array}$ & $\begin{array}{l}\text { Minimizar riscos de } \\
\text { má aceitação/ } \\
\text { conflitos }\end{array}$ \\
\hline Mídia & & & Cobertura favorável & $\begin{array}{l}\text { Minimizar risco } \\
\text { de cobertura } \\
\text { desfavorável }\end{array}$ \\
\hline $\begin{array}{l}\text { Ativistas, grupos e } \\
\text { movimentos }\end{array}$ & $\begin{array}{l}\text { Aportes } \\
\text { sóciocultural } \\
\text { diversos }\end{array}$ & $\begin{array}{l}\text { Proteção ambiental. } \\
\text { Respeito aos direitos } \\
\text { de minorias. } \\
\text { Respeito aos } \\
\text { acordos salariais, } \\
\text { etc. }\end{array}$ & & $\begin{array}{l}\text { Minimizar riscos de } \\
\text { boicote }\end{array}$ \\
\hline
\end{tabular}

Fonte: Machado et al., 2006. 
Tabela 1: Oportunidades e possíveis riscos dos stakehorlders à organização

\begin{tabular}{|c|c|c|c|c|}
\hline $\begin{array}{l}\text { Stakeholders } \\
\text { envolvidos }\end{array}$ & Contribuição & $\begin{array}{l}\text { Demandas } \\
\text { básicas }\end{array}$ & Oportunidades & $\begin{array}{l}\text { Minimização de } \\
\text { riscos }\end{array}$ \\
\hline $\begin{array}{l}\text { Investidores, } \\
\text { acionistas }\end{array}$ & Capital & $\begin{array}{l}\text { Lucros e dividendos. } \\
\text { Preservação do } \\
\text { patrimônio. }\end{array}$ & Geração de valor & $\begin{array}{l}\text { Lucros e dividendos } \\
\text { Preservação do } \\
\text { patrimônio. }\end{array}$ \\
\hline Funcionários & $\begin{array}{l}\text { Mão de obra } \\
\text { Criatividade } \\
\text { Ideias }\end{array}$ & $\begin{array}{l}\text { Salários justos. } \\
\text { Segurança no } \\
\text { emprego. Realização } \\
\text { pessoal. } \\
\text { Condições de } \\
\text { trabalho. }\end{array}$ & $\begin{array}{l}\text { Aumento do } \\
\text { comprometimento }\end{array}$ & $\begin{array}{l}\text { Minimizar riscos de } \\
\text { comportamento. }\end{array}$ \\
\hline Consumidores & Dinheiro & $\begin{array}{l}\text { Segurança e boa } \\
\text { qualidade dos } \\
\text { produtos. Preço } \\
\text { acessível. } \\
\text { Propaganda } \\
\text { honesta. }\end{array}$ & Fidelização & $\begin{array}{l}\text { Minimizar riscos de } \\
\text { má aceitação }\end{array}$ \\
\hline $\begin{array}{l}\text { Agentes regulado- } \\
\text { res, governo }\end{array}$ & $\begin{array}{l}\text { Suporte } \\
\text { institucional, } \\
\text { jurídico e político }\end{array}$ & $\begin{array}{l}\text { Obediência às leis. } \\
\text { Pagamento de } \\
\text { tributos. }\end{array}$ & Ação legal favorável & $\begin{array}{l}\text { Minimizar riscos de } \\
\text { ação legal }\end{array}$ \\
\hline $\begin{array}{l}\text { Parceiros comerci- } \\
\text { ais, fornecedores }\end{array}$ & Mercadorias & $\begin{array}{l}\text { Respeito aos } \\
\text { contratos. } \\
\text { Negociação leal. }\end{array}$ & Colaboração & $\begin{array}{l}\text { Minimizar riscos de } \\
\text { defecção. }\end{array}$ \\
\hline Concorrentes & $\begin{array}{l}\text { Competição; } \\
\text { referencial de } \\
\text { mercado }\end{array}$ & $\begin{array}{l}\text { Lealdade na } \\
\text { concorrência }\end{array}$ & & \\
\hline
\end{tabular}

Fonte: Machado et al., 2006.

Robbins (1999) observa que existe a obrigação social - ou seja, quando a empresa somente persegue metas sociais na medida em que elas contribuam para seus propósitos econômicos - e a Responsabilidade Social - que vai além do mero cumprimento das imposições financeiras e legais básicas, buscando objetivos de longo prazo que sejam bons para a sociedade, mas que, em qualquer uma das hipóteses, representem menores embates com os stakeholders. 


\section{Proposta de Modelo de Maturidade em Responsabilidade Socioambiental Corporativa}

As referências práticas e teóricas demonstraram exemplos utilizados no Brasil e no mundo sobre Responsabilidade Socioambiental Corporativa, tanto de instituições privadas quanto de ONGs. O presente estudo buscou definir um modelo hipotético de análise (conforme Figura 1), considerando os aspectos comuns encontrados e adotados globalmente, mas acrescentando o efeito das variáveis "valor da marca", "reputação da empresa", "satisfação dos stakeholders" e "risco de externalidades (negativas)". Isso permitiu uma análise dos impactos da RSAC sobre as organizações e a identificação de correlações que justifiquem investimentos Socioambientais ou se, na prática, tais ações representam custos indesejados, mas necessários, sem retorno para as empresas.

Denominado Modelo de Maturidade em Responsabilidade Socioambiental Corporativa Setorial, a representação procura demonstrar, por meio de uma escala de medição de seis âncoras, variando de 0 a 5 , a posição estimada da empresa, comparando com três pontos de referência (desempenho desejado, padrão internacional e melhores práticas). Seguindo o modelo do COBIT Management Guidelines (2000) e o adaptando às práticas e percepções de resultados em Responsabilidade Socioambiental Corporativa, a escala tem as seguintes âncoras: (0) Inexistente: ausência total de processos identificáveis, quando o setor não reconhece que a RSAC é um aspecto a ser considerado; (1) Inicial: há evidências de que o setor reconhece que o aspecto existe e deve ser considerado; entretanto, não há processos padronizados, apenas abordagens eventuais que tendem a ser aplicadas em bases isoladas, filantrópicas; (2) Repetitivo: as técnicas referentes foram desenvolvidas até o estágio em que ações similares são adotadas por organizações distintas que utilizam a prática da RSAC; contudo, não há treinamento ou divulgação formal nas empresas que compõem o setor; (3) Definido: o setor demonstra procedimentos padronizados e documentados, bem como divulgados, através de treinamento; no entanto, tais procedimentos, em si, não são sofisticados, apresentando ao setor apenas um nível básico de ações em Responsabilidade Socioambiental; (4) Gerenciado: aqui, é possível monitorar e mensurar o cumprimento dos processos, bem como avaliar se as medidas em RSAC não estão funcionando efetivamente; os procedimentos estão sob melhoria contínua e propiciam boas práticas; os impactos positivos 
das ações são percebidos, mas ainda incipientes. (5) Otimizado: os processos foram refinados ao nível das melhores práticas, com base nos resultados de progressos contínuos e exemplo de maturidade de outras organizações e setores; a RSAC é utilizada como um modelo, sendo considerada essencial para a sustentabilidade e maximização dos lucros organizacionais.

Observa-se que a proposição do trabalho é avaliar o Desenvolvimento da Responsabilidade Socioambiental Corporativa e a percepção do setor em relação aos benefícios oriundos desse processo, bem como pontuar o seu grau de maturidade do mesmo. Dessa forma, uma organização pode se situar quanto às práticas Socioambientais, em relação aos concorrentes diretos, $e$ adotar ações estratégicas que a capacite a atingir a média do setor ou até mesmo, suplantá-la, conquistando um diferencial competitivo a ser explorado. O modelo teórico proposto compreende sete construtos sendo seis latentes de primeira ordem e um latente de segunda ordem (conforme Figura 1), descritos pelas seguintes hipóteses tendo como elemento central o desenvolvimento e Responsabilidade Socioambiental: A RSAC contribui positiva e significativamente (=pes) para a satisfação dos stakeholders; h2: A RSAC agrega pes ao valor à marca da empresa; h3: A RSAC fortalece pes a reputação organizacional; h4: A RSAC implica pes em menores riscos externos; h5: Responsabilidade ambiental impacta pes no RSAC e h6: Responsabilidade social impacta pes no RSAC. 


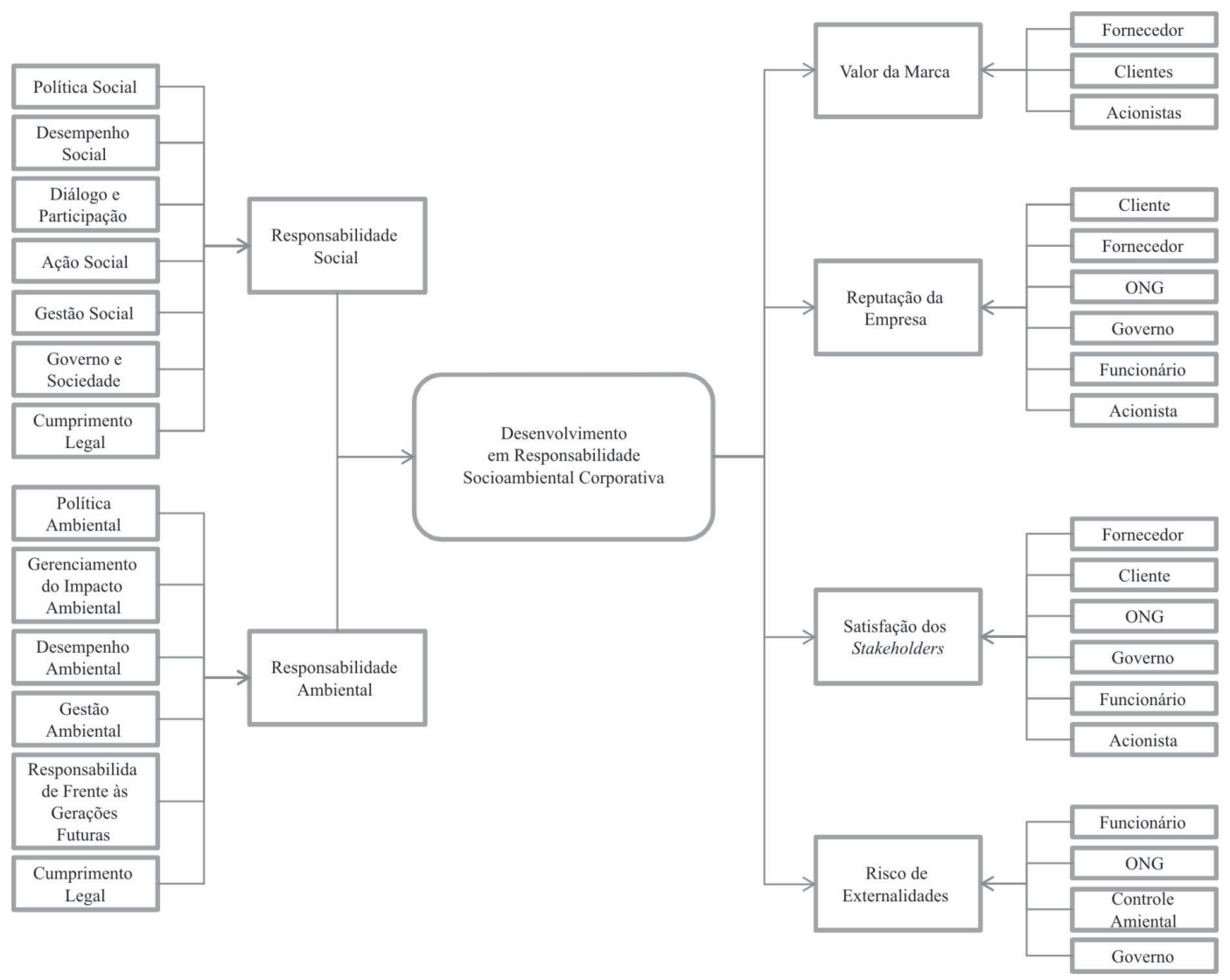

Figura 1: Modelo de maturidade em Responsabilidade Socioambiental Corporativa Setorial Fonte: Elaborada pelos autores

\section{Metodologia}

Este estudo foi realizado com base no método quantitativo (paradigma positivista), através do qual foram analisados indicadores sociais e ambientais, valor da marca, reputação da empresa, satisfação dos stakeholders e risco de externalidades, utilizando-se uma escala tipo Likert com âncoras de 0 (discordo totalmente) a 10 (concordo totalmente). As unidades de analise foram compostas por empresas do setor de construção civil localizadas dentro e no entorno da cidade de Belo Horizonte. As unidades de observação são os gerentes e os diretores das empresas nesse setor. A amostragem foi feita 
mediante uma lista das firmas obtidas pelo sindicato local e foi realizado o contato telefônico convidando os dirigentes para participarem da pesquisa.

Os dados secundários foram obtidos por meio de bibliografia - artigos, livros, teses, monografias e pesquisas na Internet - e os primários com o uso de um survey, composto por 31 questões, aplicado nos gestores do setor da indústria da construção civil, cuja amostra foi de 200 empresas. As informações foram tabuladas e armazenadas em um banco de dados (Microsoft Office Excel e SPSS), para posterior estudo. Os softwares SPSS 13, SMARTPLS e Latent Variable Partial Least Square (LVPLS) constituíram-se ferramentas de verificação estatíticocientífica, utilizadas para exame de equações estruturais.

\section{Análise dos Dados e Discussão dos Resultados}

Após as análises exploratória e validação (descritiva, de dados ausentes, de avaliação da normalidade, de outliers e de estudo de linearidade, redundância e multicolinearidade) e da qualidade de mensuração (dimensionalidade, confiabilidade e validade do modelo) o modelo de estudo foi reduzido de 31 indicadores iniciais para 21 (redução de 9 indicadores). Vale mencionar que esse número de indicadores é interessante pela significativa parcimônia na mensuração do modelo proposto. $\mathrm{O}$ quadro 3 mostra valores altos e significativos para a correlação dos vários construtos em relação a RSAC.

\begin{tabular}{|l|l|l|l|l|l|l|l|}
\hline Construtos & $\mathrm{F}$ & 1 & 2 & 3 & 4 & 5 & 6 \\
\hline Risco de Externalidade (negativa) & 1 & $\mathbf{0 , 7 3}$ & & & & & \\
\hline Responsabilidade Ambiental & 2 & $\mathbf{0 , 3 8}$ & $\mathbf{0 , 5 5}$ & & & & \\
\hline Reputação da empresa & 3 & 0,27 & $\mathbf{0 , 4 4}$ & $\mathbf{0 , 6 8}$ & & & \\
\hline Responsabilidade Social & 4 & 0,17 & $\mathbf{0 , 3 6}$ & $\mathbf{0 , 3 4}$ & $\mathbf{0 , 4 8}$ & & \\
\hline Satisfação dos stakeholders & 5 & 0,27 & $\mathbf{0 , 4 6}$ & $\mathbf{0 , 7 8}$ & $\mathbf{0 , 3 6}$ & $\mathbf{0 , 6 2}$ & \\
\hline Valor da marca & 6 & 0,27 & $\mathbf{0 , 4 6}$ & $\mathbf{0 , 5 6}$ & 0,29 & $\mathbf{0 , 5 5}$ & $\mathbf{0 , 8 6}$ \\
\hline
\end{tabular}

Obs.: Os valores na diagonal principal correspondem à variância média extraída dos construtos.

Quadro 3: Avaliação da validade discriminante dos construtos

Fonte: Dados da pesquisa (2008) 
Os valores abaixo da diagonal correspondem ao quadrado do coeficiente de correlação entre os valores fatoriais da amostra, estimados pelo PLS.

Os valores dos coeficientes das equações estruturais, obtidos com os dados padronizados, que melhor explicam o construto "Responsabilidade Social Corporativa" são: "Desempenho Social", 0,442; "Diálogo e Participação", 0,242; "Gestão Social”, 0,457; e "Cumprimento Legal”, 0,266. O "Desempenho Social" trata da diversidade de sexo e cor, bem como de remuneração compatível, inclusive para serviços terceirizados; e o item "Diálogo e Participação" indica gestão participativa. Ambos, "Desempenho Social" e "Diálogo e Participação" referem-se ao ambiente interno da organização. Os dirigentes orientados para desempenho plural (rentabilidade financeira, satisfação de stakeholders, RSAC, entrega de valor pela inovação) da firma devem atentar pelas ações internas e externas que tem repercussão na sobrevida da organização. Devem analisar indicadores de qualidade de Gestão Social, com programas e projetos próprios, voltados para a comunidade e planejados para atendimento do "Cumprimento Legal" relacionado à dimensão social do consumo e à atenção a sanções judiciais e administrativas.

No que tange à "Responsabilidade Ambiental", os valores dos coeficientes - a exemplo da "Responsabilidade Social" (dois internos e dois externos) - que se apresentam mais compatíveis com a formação deste construto são: "Política Ambiental", 0,265; "Desempenho Ambiental", 0,484; "Gestão Ambiental", 0,141; e "Cumprimento Legal", 0,371. A "Política Ambiental" concerne-se à adoção de conduta formal e estratégica, metas e divulgação; o "Desempenho Ambiental" responde pela ecoeficiência, com a utilização dos 3Rs (reaproveitamento, reuso e reciclagem), inclusive no tratamento dos resíduos e efluentes; a "Gestão Ambiental" contempla a relação com os stakeholders externos; e o "Cumprimento Legal" cuida de licença ambiental para todos os projetos, instalações e operações.

Revela-se que a "Responsabilidade Ambiental" possui maior peso na consolidação do desenvolvimento em RSAC. Assim, o fator meio ambiente é percebido pelos gestores com maior poder de influência entre os stakeholders e, por conseguinte, na instalação dos construtos finais do modelo, traduzindose em benefícios mais palpáveis para a organização. 


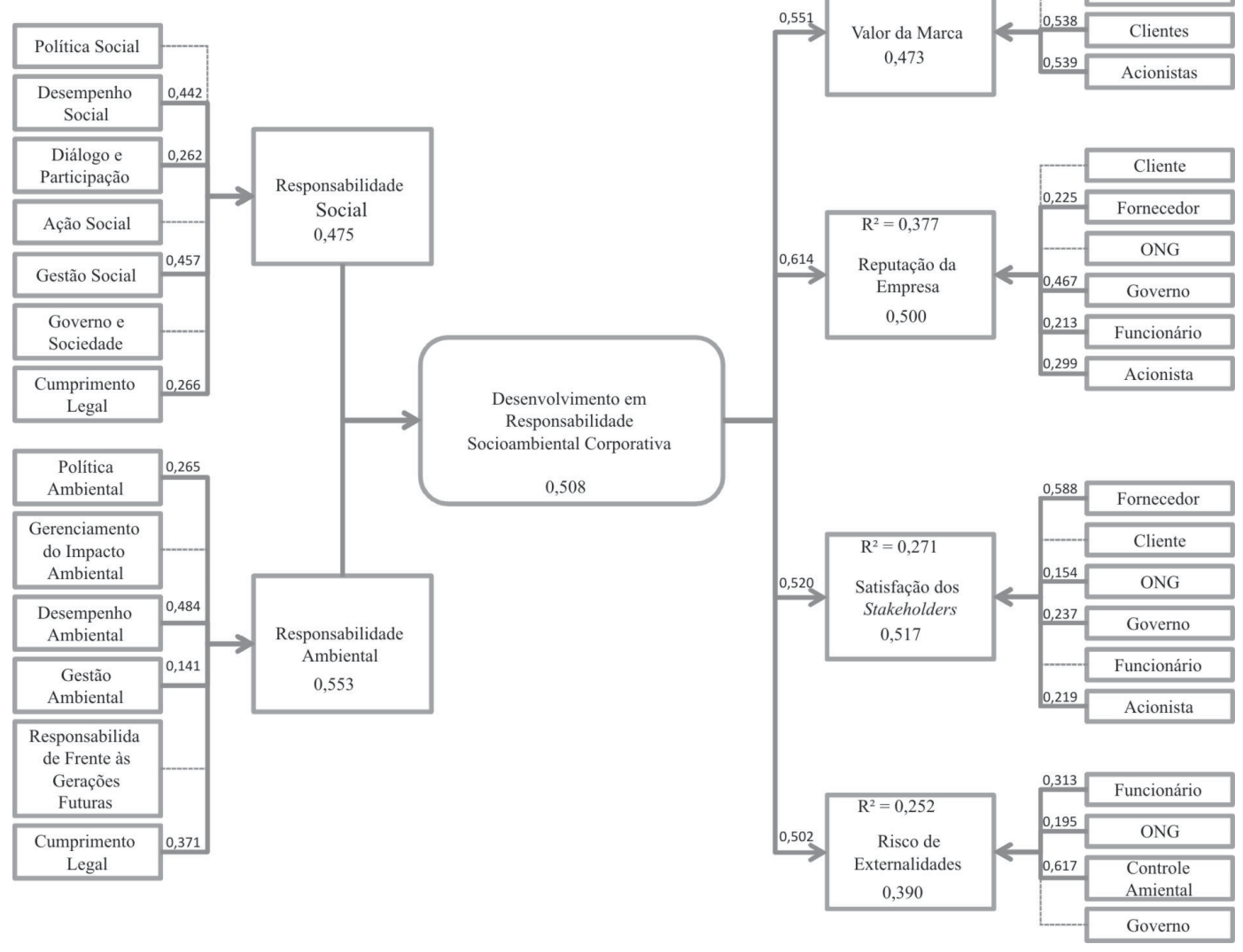

Figura 2: Modelo operacional de maturidade em Responsabilidade Socioambiental Corporativa Setorial Fonte: Dados da pesquisa (2008)

Os construtos finais, representados pela ação do desempenho em RSAC das partes envolvidas ou interessadas, foram aqui analisados por meio da Satisfação dos Stakeholders (comunalidade de 0,517 e $\mathrm{R}^{2}=0,271$ ), da Reputação da Empresa (comunalidade de 0,500 e $\mathrm{R}^{2}=0,377$ ), do Valor da Marca (comunalidade de 0,473 e $\mathrm{R}^{2}=0,303$ ) e do Risco de Externalidades (comunalidade de 0,390 e $\mathrm{R}^{2}=0,252$ ). Este último mostra que os riscos são minimizados pela adoção da RSAC, principalmente em relação aos funcionários (ações trabalhistas), ONGs (pressão externa representativa da sociedade) e controle ambiental (multas e/ou sanções) aplicadas por órgãos públicos administradores desta área. A diminuição desses fatores negativos implica em maior tranquilidade para que a empresa possa se dedicar às suas atividades principais, resultando em probabilidade de qualidade e lucro para a organização. 
Os stakeholders satisfeitos com a RSAC, na visão dos gestores, são os fornecedores (parceria fortificada), as ONGs (respeito com os funcionários, a comunidade e o meio ambiente), o Governo (acatamento às leis e aos serviços prestados à sociedade) e os acionistas (crescimento da sustentabilidade $e$ lucratividade da empresa). No construto Valor da Marca, o cliente (novos consumidores e lealdade) surge como forte referência para a prática e manutenção da RSAC, demonstrando que tais ações influenciam no momento da decisão de compra. Isso esclarece porque o indicador acionista (captação e manutenção de investidores) se revela em igualdade de peso, pois as práticas em RSAC são atrativas no mercado consumidor, estimulando mais investimentos.

Por último, e não menos importante, o construto Reputação da Empresa mostrou ser também de impacto significativo e positivo na RSAC, principalmente entre os fornecedores (seriedade e capacidade de cumprir compromissos), o Governo (negociações com o poder público), os funcionários (orgulho da organização) e os acionistas (confiabilidade).

Apesar de quatro indicadores, dois da responsabilidade social e outros dois da responsabilidade ambiental demonstrar baixa significância para o setor estudado, o modelo teórico proposto confirmou as hipóteses desenhadas, quais sejam: A RSAC contribui positiva e significativamente (pes) para a satisfação dos stakeholders; h2: A RSAC agrega pes ao valor à marca da empresa; h3: A RSAC fortalece pes a reputação organizacional; h4: A RSAC implica pes em menores riscos externos; h5: Responsabilidade ambiental impacta pes no RSAC; e h6: Responsabilidade social impacta pes no RSAC.

Verifica-se que o modelo estrutural proposto expressa coerência e capacidade para explicar os efeitos da RSAC na sustentabilidade empresarial. Dessa forma, a pesquisa evidencia que é possível a mensuração dessas ações em fatores importantes para a conquista de competitividade, possuindo razões satisfatórias para que a Responsabilidade Socioambiental deixe de ser periférica e adquira posição estratégica, recebendo, como tal, maior atenção nos planos e projeções estipulados pela alta direção. 


\section{Cálculo de Maturidade em Responsabilidade Socioambiental Corporativa Setorial}

Utilizando-se as sugestões de Kline (1998), empregou-se a média ponderada dos valores obtidos nos pesos estruturais, para calcular médias dos fatores (MF) de cada um dos construtos. Esse procedimento foi delineado no intuito de calcular índices globais de Responsabilidade Social, Ambiental e Socioambiental Corporativa (RSAC). Considerando a estrutura formativa do modelo, os indicadores considerados nesta análise foram os que compõem as escalas de Responsabilidade Social e Responsabilidade Ambiental. A proposta de Kline usa a seguinte fórmula, que foi aplicada:

$$
M F_{i}=\frac{\sum_{I=1}^{K} W_{K} X_{K I}}{\sum_{I=1}^{K} W_{K}} \ldots \ldots \ldots \ldots \ldots \ldots \ldots . . . \ldots \text { Equação } 1
$$

Em que:

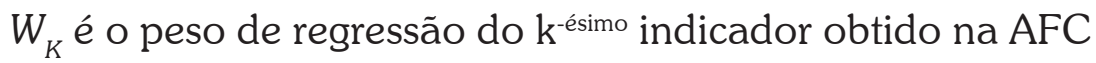

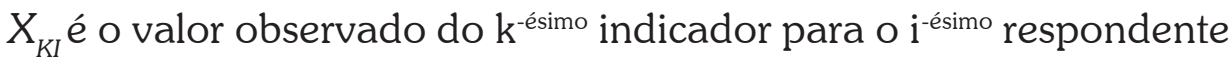

Desse modo, efetuou-se o cálculo de um índice para Responsabilidade Ambiental, Social e outro para RSAC, demonstrados na Figura 3, apontando uma escala de maturidade 4 (gerenciada), conforme os níveis de observação assim definidos: Nível 0 (Inexistente) - médias 0,00 a 0,99; Nível 1 (Inicial) médias 1,0 a 2,99; Nível 2 (Repetitivo) - médias 3,0 a 4,99; Nível 3 (Definido) - médias 5,0 a 6,99; Nível 4 (Gerenciado) - médias 7,0 a 8,99; e Nível 5 (Otimizado) - médias 9,0 a 10,0. 


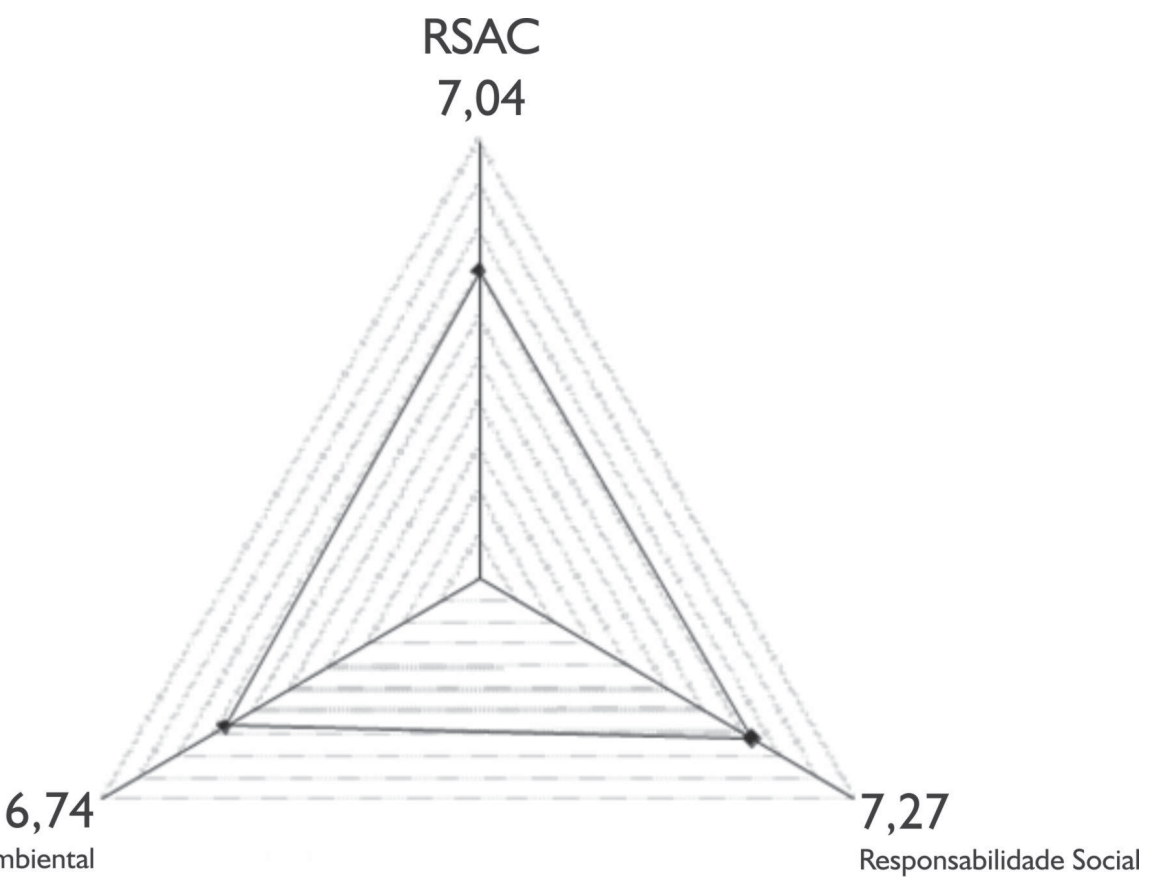

Figura 3: Índice de maturidade em Responsabilidade Socioambiental Corporativa Setorial Fonte: Dados da pesquisa (2008)

Adotando a mesma abordagem anteriormente descrita para os índices finais da representação, obtêm-se as seguintes médias de avaliação para o segmento analisado são obtidas: Valor da Marca (7,9), Reputação da Empresa (7,9), Satisfação dos Stakeholders $(7,8)$ e Risco de Externalidades $(6,0)$.

Para determinar o quanto a RSAC influencia na formação desses indicadores, propõem-se dois tipos de índices: (a) de associação média e (b) de potencial de melhoria. $\mathrm{O}$ primeiro refere-se ao poder explicativo médio da RSAC das variáveis finais do modelo e pode ser representado pela média aritmética simples dos indicadores de $\operatorname{RSAC}(0,551 ; 0,614 ; 0,520 ; 0,502)$ em seus construtos dependentes. Neste estudo, chega-se ao valor 0,547, que, multiplicado por 10 , resulta em 5,47 .

$\mathrm{O}$ índice de potencial de melhoria mostra em que proporção a RSAC pode ser usada como fonte de avanços dos construtos finais da representação. Para tanto, calcula-se o peso não-padronizado de regressão de RSAC nos indicadores finais do modelo. Depois, avalia-se em que grau será o impacto relativo sobre cada um desses índices, caso a RSAC atinja o patamar máximo. Nesse caso, a média atual de RSAC é de 7,04. Se a RSAC alcançar a excelência 
de 10 pontos (isto é, se todas as empresas passarem a atuar o máximo possível dentro da RSAC), haverá um acréscimo relativo de 2,96 do potencial de melhoria. O impacto esperado como resultado da representação seria, então, igual ao valor deste aumento multiplicado pelo valor do peso não padronizado de cada índice $(2,25 ; 2,15 ; 2,33 ; 2,95)$. Somando essa elevação à média de cada indicador, chega-se a importâncias que extrapolam o limite máximo da escala para os três primeiros resultados do modelo, estabelecendo, portanto, o valor restrito de dez pontos. Realizando-se a razão entre os índices e se subtraindo uma unidade, atinge-se o valor que representa o potencial que a RSAC tem de determinar em crescimento nos resultados finais do setor em questão (Quadro 4).

\begin{tabular}{|l|c|c|c|c|}
\hline \multicolumn{1}{|c|}{ IND. } & PESOS & MÉDIA & MÉDIA POTENCIAL & $\%$ \\
\hline Valor da Marca & 0,76 & 7,87 & 10,00 & $27,1 \%$ \\
\hline Reputação da Empresa & 0,73 & 7,94 & 10,00 & $25,9 \%$ \\
\hline Satisfação dos Stakeholders & 0,79 & 7,81 & 10,00 & $28,0 \%$ \\
\hline Risco de Externalidade (negative) & 1,00 & 6,03 & 8,98 & $48,9 \%$ \\
\hline MÉDIA & 0,82 & 7,41 & 9,74 & $32,5 \%$ \\
\hline
\end{tabular}

Quadro 4: Avaliação de Média Potencial

Fonte: Dados da pesquisa (2008)

Pode-se, então, usar a média desses índices de crescimento como o potencial estratégico da RSAC no setor, que, neste caso, é 32,5\%.

POTENCIAL ESTRATÉGICO DO RSAC $=\frac{\sum_{i=1}^{k}\left[\left(10-R S A C_{\text {setor }}\right) \times \beta_{k}+{\left.\text { Média } \text { Setorial }_{k}\right]}_{\sum_{i=1}^{k} \text { Média Setorial }}\right.}{\text { Sel }_{k}}-1$ ...... Equação 2

Com base nesses pesos, é possível também definir o potencial relativo de melhoria nos resultados finais da RSAC, caso sejam implementadas mudanças em particular na organização. Se, por exemplo, uma empresa fosse avaliada com média de seis pontos (abaixo da média do segmento), poderia se analisar o impacto relativo da equiparação da RSAC da corporação à média do setor. Basta verificar qual o impacto do aumento ( $\mathrm{Ik}=$ média do setor média da empresa; sendo k uma empresa qualquer), sobre os índices finais 
da RSAC. Somando esse crescimento médio à média atual dos resultados, chega-se ao potencial de melhoria para aquela organização, ao se equiparar ao segmento.

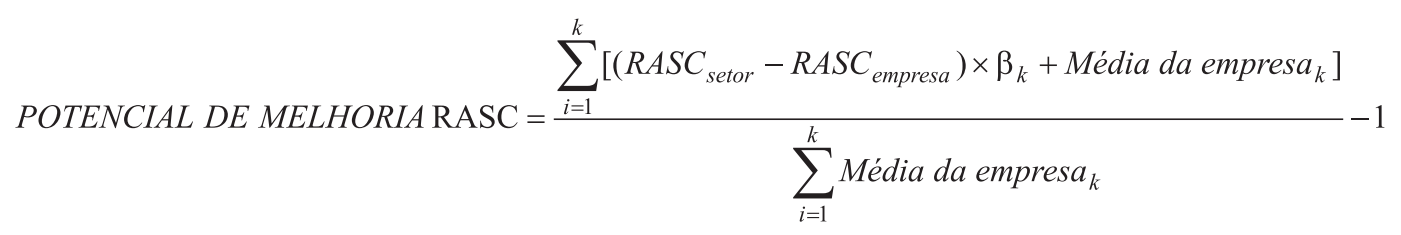

\section{Equação 3}

O cálculo de potencial de melhoria da Responsabilidade Socioambiental Corporativa pode ir além, isto é, se as dimensões avaliadas forem consideradas estratégicas por uma determinada empresa, ela terá condições de verificar quanto precisa investir para se sobrepor à média do setor e em qual construto terá maior resultado, com possibilidade de atingir um índice superior, que, em tese, proporcionará um diferencial competitivo a ser explorado.

\section{Considerações Finais}

O modelo proposto teórico mostrou-se aderente com a matriz empírica, salientando que o "Desenvolvimento em Responsabilidade Socioambiental Corporativa" apresenta elevado peso na intermediação das ações de responsabilidade Socioambiental e o desempenho da firma medido pelo valor da marca, reputação, riscos e satisfação de stakeholders. Evidencia-se além de assertivas qualitativas, por meio de mensuração quantitativa, o quantum que esse construto central é explicado pelos por ações sociais e ambientais praticadas e seus efeitos sobre os consequentes. No caso, percebeu-se que a "Responsabilidade Ambiental" tem maior impacto sobre o desenvolvimento de RSAC (coeficiente de valor de 0,553) que a "Responsabilidade Ambiental" (coeficiente de valor de 0,475 ), correspondendo a $16 \%$ a maior. Como explicação nos consequentes mediu-se que as ações em "Desenvolvimento em Responsabilidade Socioambiental Corporativa" conseguem explicar de forma significativa as dimensões: Valor da Marca, Reputação da Firma, Satisfação de stakeholders, Risco de externalidades, podem ser considerados 
indicadores de alto desempenho e sustentabilidade de uma organização (negócio ou corporativo).

Foi medido, dessa forma, que a RSAC tem significativo peso como fator intermediador, devendo figurar, sistematicamente, no planejamento estratégico organizacional com o mesmo destaque dos fatores desenvolvidos pela economia clássica. Pois, afinal, como foi medido, um diferencial, que pode contribuir para a competitividade, lucratividade e sustentabilidade empresarial.

Não obstante, como desempenho significa concentrar os recursos disponíveis onde estão os resultados, percebe-se, sob uma análise crítica, que os investimentos no meio ambiente são mais relevantes. Ou seja, o impacto ambiental afeta diretamente cada parte interessada, demonstrando um sentido mais "egocêntrico" dos recursos empresariais. Isso sugere, adicionalmente, que as empresas podem estar mais atuantes no sentido de atender regulação ambiental (maior pró-atividade), mais penalizadora ou passível de atendimento legal, em lugar de aplicações em projetos sociais (ações mais reativas). Também se pode ter o sentimento de que ação social é mais uma responsabilidade do estado e questão ambiental é pertinente às firmas, de onde tiram maior ou menor benefício, requerendo sua maior atenção.

Independente desta consideração, isto é, onde cabe maior desempenho, o setor pesquisado demonstrou um nível de maturidade em RSAC gerenciado, podendo, assim, ser melhorado. Além disso, o modelo proporciona condições de mensuração, que favorecem empresas a identificarem sua posição em relação à média do seu segmento e, dessa forma, avaliarem se é necessário investir mais e onde, para atingirem um diferencial competitivo. Dessa maneira, a representação define não somente o nível de maturidade atual como também o quanto pode aperfeiçoar-se, para que a RSAC contribua ao máximo nos construtos finais, agregando resultados satisfatórios em fatores considerados pela academia e pelo empresariado como relevantes na condução dos negócios e na valorização ao longo do tempo.

Foi estimado que ambos os valores dos indicadores para Responsabilidade Ambiental e Social se encontram (6,74 e 7,27, respectivamente), em uma escala lilert de 0 a 10 de ancoras, se encontram posicionados no $3^{\circ}$ quartil e, no caso a média $(7,00)$ estimada também. Assim, pode-se considerar que o setor possui uma posição alta para o Índice de maturidade em Responsabilidade Socioambiental Corporativa Setorial. 


\section{Social end Environmental Corporate Responsibility end Maturity Indicator Mediating Organizations Strategic Performance}

\section{Abstract}

The business environment has presented constant challenges to organizations leaders. In this context, permanent surveillance, reflecting the search for competitiveness and productivity, causes them turn attention to factors or actions antecedents and consequences of corporate social and environmental responsibility dimension (RSAC). The paper analyzes and estimates the intensity of the relations between the factors of brand value, reputation sense of the company concerned (stakeholders) and perspective to generate external risks, all of them such as satellites explaining the RSAC. And, in addition to tests of goodness of fit to the relational model, also was proposed an equation to measure the degree (or index) of maturity in Environmental Responsibility Corporate Sector (RSACS), attempting to analyze and identify in what stage the RSACS constructs affects the final performance as strategic for organizations. This research was performed in the construction of Minas Gerais, represented by their managers adopting a survey method using a structured questionnaires with questions based on likert variations. The data collected were evaluated by analysis of structural equations using LVPLS. To measure the shares in Environmental Responsibility, we used known models in organizations and academia, such as the Corporate Sustainability Index, the Dow Jones Indexes, the index of the Ethos Institute and the representation theory of Hopkins (1997).

Key-words: Mature model of social and environmental responsibility. Maturity model index. Strategy of Corporate social and environmental. Corporate responsibility. Sustainable business.

\section{Referências}

ASHLEY, P. A. Ética e responsabilidade social nos negócios. São Paulo: Saraiva, 2002.

BERNARDO, D. Carneiro dos Reis et al. Responsabilidade Social Empresarial: uma análise dos balanços sociais das sociedades anônimas de capital aberto. In: Encontro Nacional de Pós-Graduação e Pesquisa em AdministraçãoEnANPAD, 29, 2005, Brasília. Anais... Brasília: ANPAD, 2005. 
CARROL, A. B. The pyramid of corporate social responsability: toward the moral management of organization stakeholders. Business Horizons, New York, Elsevier, v. 34, n. 4, p.39-48, jul./aug. 1991.

COMISSÃO DA COMUNIDADE EUROPEIA. Promoting a European framework for Corporate Social Responsibility. (Livro Verde). Bruxelas, 2001.

CORAL, E. O planejamento estratégico e a formulação de estratégias econômicas, sociais e ambientais: uma proposta em busca da sustentabilidade empresarial. 2002. Tese (Doutorado). Universidade Federal de Santa Catarina. Santa Catarina, 2002.

CORAZZA, R. I. Gestão ambiental e mudanças da estrutura organizacional. RAE-eletrônica, v. 2, n. 2, jul-dez/2003. Disponível em: <http://www.rae.com.br/eletronica/index.cfm?>. Acesso em: 15 mar. 2008.

CORPORATE REPUTATION WATCH 2006. Return on reputation. Disponível em <http://www.hkbrasil.com.br/index/acao/arquivos/ crw2006.pdf>. Acesso em: 4 set. 2008.

CÔRTE-REAL, A. Perspectivas sobre o valor da marca. Portugal: Faculdade de Economia da Universidade do Porto, 2005.

ELKINGTON, J. Cannibals with forks: the triple bottom line of 21st century business. London: Capstone, 1998.

GLOBAL REPORTING INITIATIVE. Diretrizes para Relatórios de Sustentabilidade. Amsterdã, 2006. Disponível em: < http:// www.globalreporting.org/NR/rdonlyres/812DB764-D217-4CE8-B4DE15F790EE2BF3/0/G3_GuidelinesPTG.pdf>. Acesso em: 21 jun. 2008.

GOLDENBERG, Miriam et al. Ecologia, ciência e política: participação social, interesses em jogo e luta de idéias no movimento ecológico. Rio de Janeiro: Revan, 1992.

GONÇALVES FILHO, Cid. Brand equity baseado no consumidor: desenvolvimento e validação de um instrumento de mensuração no setor automotivo. In: Encontro Nacional de Pós-Graduação e Pesquisa em Administração-EnANPAD, 30., 2006, Salvador. Anais... Salvador: ANPAD, 2006. 
GRAJEW, Oded. Ganhos e custos da responsabilidade social. Valor Econômico. Rio de Janeiro, 29 jan. 2002. Disponível em: <http://www.valoronline.com.br>. Acesso em: 22 jun. 2008.

HAENLEIN, M.; KAPLAN, A.M. A beginner's guide to partial least squares (PLS) analysis. Understanding statistics. 3(4), 283-297, 2004.

HOPKINS, Michael. Difining indicators to assess socially responsible enterprises. Kidlington: Futures, 1997.

INSTITUTO ETHOS DE EMPRESAS E RESPONSABILIDADE SOCIAL. Responsabilidade social das empresas: percepção do consumidor brasileiro. São Paulo, 2000. Disponível em: <http://www.ethos.org.br>. Acesso em: 21 out. 2007.

KLINE, R. B. Principles and practice of structural equation modeling. New York: The Guilford Press, 1998.

MACHADO, R. T. M.; BERNARDO, D. Carneiro dos Reis; PEREIRA, Nádia Campos; PESSANHA, Gabriel Rodrigo Gomes. Investimentos ambientais e sociais externos: um estudo comparativo das companhias de capital aberto no Brasil. In: Encontro Nacional de Pós-Graduação e Pesquisa em AdministraçãoEnANPAD, 30, 2006, Salvador. Anais... Salvador: ANPAD, 2006.

MAIA, C. Responsabilidade Social no Brasil. Revista Exame fórum: um amplo e variado painel da cidadania corporativa do país, n. 855, 2005.

MELO NETO, Francisco P. de; FROES, César. Gestão da responsabilidade social corporativa: o caso brasileiro. Rio de Janeiro: Qualitymark, 2001.

MITCHELL, R. K.; AGLE, B. R.; WOOD, Donna J. Toward a theory of stackholder identification and salience: defining the principle of who and what really counts. Academy of Management Review, Nova Iorque, v. 22. n. 4, p. 853-886, 1997.

OLIVEIRA, D. F. Relações entre a Reputação e o Valor da Marca no Setor Automotivo. In: Encontro Nacional de Pós-Graduação e Pesquisa em Administração-EnANPAD, 31., 2007, Rio de Janeiro. Anais... Rio de Janeiro: ANPAD, 2007. 
PASSUELLO, C. Benevenuti; SOUZA, Yeda Swirski. Confiança e risco em processos decisório. In: Encontro Nacional de Pós-Graduação e Pesquisa em Administração-EnANPAD, 29., 2005, Brasília. Anais... Brasília: ANPAD, 2005.

PORTER, M. E.; LINDE, Class van der. Green and competitive: ending the stalemate. Harvard Business Review, v. 73, n. 5, p. 120- 134, 1995 b.

ROBBINS, Stephen P. Comportamento organizacional. Rio de Janeiro: LTC, 1999.

THOMAZ, J. C.; BRITO, E. P. Z. Reputação corporativa e seus construtos formativos: Implicações para a Gestão e Vantagem Competitiva. In: Encontro Nacional de Pós-Graduação e Pesquisa em Administração-EnANPAD, 31. 2007, Rio de Janeiro. Anais... Rio de Janeiro: ANPAD, 2007.

XAVIER, A. Moura; SOUZA, Washington José. Responsabilidade social empresarial: estudo teórico-empírico à luz dos instrumentos Ethos. In: Encontro Nacional de Pós-Graduação e Pesquisa em Administração-EnANPAD, 27. 2003, Atibaia, São Paulo. Anais... Atibaia: ANPAD, 2003. 